AWEJ for Translation \& Literary Studies, Volume3, Number1. February 2019

DOI: http://dx.doi.org/10.24093/awejtls/vol3no1.5

Pp.66-73

\title{
Inconsistent Linguistic Functional Behaviours of Particle 4 in the Holy Quran: A Critique of the Holy Quran Translation
}

\author{
Eyhab Abdulrazak Bader Eddin \\ English Department, faculty of Languages and Translation \\ King Khalid University, Saudi Arabia
}

\begin{abstract}
Buried in the quicksand of ignorance and drowned in the deep reticence of the sea of linguistics, Arabic particles in general, and particle s in particular have received little attention on translators' part. This paper carefully examines the most widely-read translations of particle s as held up through the Quran. It is a critique of the translation of the Quran. Contrary to the long-standing concept which perceives هل هل as solely an interrogative particle, this paper crosses t's and dots i's in relation to focusing translators' attention on other almost-overlooked linguistic functions carried by هل, i.e. corroborative, negative and imperative. It is found that particle هل in all contexts is dealt with from the same perspective in the translations. This entails the translators' failure to understand the inconsistent linguistic behaviors of هل. This paper has put efforts to plumb the depths of identifying the different functions expressed by هل, which have long stood in the face of translators, a knotty problem that has long escaped the notice of translators, and thus yielded inaccurate renditions of the هل This paper may open up new horizons for scholars in their future studies, and act as a bedrock for researchers to follow suit.
\end{abstract}

Keywords: Corroborative, imperative, interrogative, linguistic functions, Particle هل, Quran, translation

Cites as: Bader Eddin, E. A.(2019). Inconsistent Linguistic Functional Behaviours of Particle in the Holy Quran: A Critique of the Holy Quran Translation. Arab World English Journal for Translation \& Literary Studies, 3 (1) 66-73.

DOI: http://dx.doi.org/10.24093/awejtls/vol3no1.5 